\title{
Tarım işletmelerinde girişimcilik düzeyinin belirlenmesi
}

\section{Determination of entrepreneurship level in agricultural enterprises}

\author{
Zeki BAYRAMOĞLU1 ${ }^{1}$, Kemalettin AĞIZAN ${ }^{1 *}$ \\ ${ }^{1}$ Selçuk Üniversitesi Ziraat Fakültesi Tarım Ekonomisi Bölümü \\ ${ }^{1}$ Selçuk Üniversitesi Ziraat Fakültesi Tarım Ekonomisi Bölümü
}

\section{To cite this article:}

Bayramoğlu, Z. \& Ağızan, K. (2019). Tarım işletmelerinde girişimcilik düzeyinin belirlenmesi. Harran Tarım ve Gıda Bilimleri Dergisi, 23(2): 234246. DOI:

10.29050/harranziraat.482352

\section{Address for Correspondence: Kemalettin AĞIZAN e-mail: \\ agizankemalettin@gmail.com}

\section{Received Date:}

13.11.2018

Accepted Date:

14.03.2019
(C) Copyright 2018 by Harran University Faculty of Agriculture. Available on-line at www.dergipark.gov.tr/harranziraat Non Commercial 4.0
Öz

Insan ihtiyaçlarını karşılamaya yönelik üretimde emek, sermaye ve doğal kaynakları kullanarak, bu üretim faktörlerinin organizasyonlarını gerçekleştirip, muhtemel riskleri alan kişi olan girişimcilerin varlığı üretimin sürdürülebilirliği açısından son derece önemlidir. Bu nedenle çalışmanın temel amacı tarım işletmelerinin girişimcilik düzeyleri belirlemektir. Araştırma bölgesi olarak tarımsal üretimin en yoğun olarak yapıldığı yer olan Konya ili Ereğli ilçesi gayeli olarak seçilmiştir. Bölgede üretim faaliyeti gösteren ve tabakalı tesadüfi örnekleme yöntemine göre belirlenen 98 tarım işletmesiyle anket yapılmış ve işletmelerin girişimcilik düzeyleri belirlenmiştir. Girişimcilik düzeyini belirlemede girişimcide olması gereken özellikler profesyonellik, yöneticilik, fırsatçılık, stratejik davranış ve iş birliği adı altında beş bileşene ayrılmıştır. Her bir bileşen kendi içinde sınıflandırılmış ve değişkenler belirlenmiştir. Belirlenen değişkenler elde edilen veriler doğrultusunda ölçeklendirilmiştir. Her bir özellik ve sınıf için değişkenlerin ortalaması alınarak skorlar belirlenmiştir. Ayrıca bütün değişkenlerin ortalaması alınarak girişimcilik katsayısı hesaplanmıştır. Bu değer işletmeler ortalamasına göre 3.75 olarak belirlenmiştir. Belirlenen bu değer sonucunda var olan girişimcilik yeteneklerinin ortaya çıkarılmasında kullanılmak üzere model önerisinde bulunulmuştur.

Anahtar Kelimeler: Girişimcilik katsayısı, Tarım işletmeleri, Tarımsal girişimcilik

\section{ABSTRACT}

Using labor, capital, and land in production to meet human needs, the existence of entrepreneurs who realize the organization of these factors of production and take the possible risks is extremely important for the sustainability of production. Therefore, entrepreneurship levels of agricultural enterprises were determined within the scope of the study. As the research region, Konya district of Ereğli province was chosen as the most intensively used agricultural production areas, and a survey was conducted with 98 agricultural enterprises which were determined according to stratified random sampling method in the region and entrepreneurship levels of enterprises were determined. In the determination of entrepreneurship levels, the characteristics that should be in the entrepreneur are divided into five components under the name of professionalism, management, opportunism, strategic behavior, and cooperation. Each component was classified within itself and variables were determined. The determined variables were scaled according to the obtained data. Scores were determined by taking the average of variables for each feature and class. Moreover, the average of all variables was determined and the entrepreneurship coefficient was determined. This value is determined as 3.75 according to the average of enterprises. As a result of this determined value, the model was suggested to be used to reveal the existing entrepreneurship skills.

Key Words: Entrepreneurship coefficient, Agricultural enterprises, Agricultural entrepreneurship 
Giriş

Geleneksel olarak tarım, çoğunlukla yeni üretim tekniklerini kullanamayan çok sayıda küçük aile işletmelerinin hâkim olduğu sınırlı dinamiklerle birlikte düşük teknolojili bir sektör olarak görülmektedir. Son yıllarda, tarım piyasalarının korunması ve hızlı değişen toplum nedeniyle bu durum önemli ölçüde değişmektedir. Tarım işletmeleri gittikçe artan bir şekilde değişen tüketici alışkanlıklarına, artan çevresel düzenlemelere, ürün kalitesine yönelik yeni gereksinimlere, değer ve tedarik zincir yönetimine, gıda güvenliğine, sürdürülebilirlik vb. gibi piyasanın değişkenlerine uyum sağlamaktadır.

Bu değişiklikler tarım sektörüne yeni girenlerin, inovasyonların ve girişimciliğin yolunu açmaktadır. Hem karar vericiler için hemde üreticiler için tarım sektörünü gelecekte sürdürülebilir kılabilmek, yöneticilik ve işgücünün yanında girişimciliğe olan intiyacı artırmaktadır. Son yıllardaki araştırmalar, tarımsal girişimciliğin sadece düşünce olarak kalmadığını göstermektedir (McElwee, 2008; Jarkko Pyysiäinen, Anderson, McElwee, \& Vesala, 2006). Bu kapsamda tarımsal girişimci tarım sektöründeki makul seviyede riskleri alan, fırsatları görebilen, üretim faktörlerini organize eden ve karı hesaplayabilen kişi olarak tanımlanabilir. Tarımsal girişimcilik ise girişimci kişinin gücüdür. Bu durumun tarım sektörünün büyümesinde ve sürdürülebilir kılınmasında önemli bir etkisi vardır (Lans, Verstegen, \& Mulder, 2011; Verhees, Kuipers, \& Klopcic, 2011).

Tarım, dünyanın en temel sektörleri arasında yer almakta ve bir milyardan fazla insan istihdam etmekte olup, küresel GSYiH'nın \%3'ünü oluşturmaktadır (FAO, 2017). Türkiye'de ise sektörler arasında çarpan etkisinin en yüksek sektör olması, toplam istihdam içindeki payının \%19 ve Milli gelire olan katkısı \%6.6 olduğu düşünüldüğünde tarım sektörü halen önemini korumaktadır (TOB, 2017). Küresel ve Türkiye ekonomisindeki payının azalmasına rağmen, gıda güvenliği ile güvencesinin artması ve temel besin maddelerinin kaynağı olması açısından tarım işletmelerinin büyümesi gerekliliği belirmiş ve bu durumun ancak girişimciliğin artırılmasıyla gerçekleşeceği ortaya çıkmıştır.

Türkiye'deki tarımsal işletmelerin yapısı incelendiğinde \%80,7'sinin 100 dekardan küçük işletme büyüklük gruplarında yer aldığı görülmektedir (TÜik, 2017). Tarım işletmelerin geçimlik aile ve küçük ölçekli olmaları işletmelerde yeniliklerin benimsenmesini zorlaştırmaktadır. Ayrıca sermaye devir hızının düşük olmasına ve tasarruf oranlarının azalmasına neden olmaktadır. Türkiye'deki işletmelerin uluslararası standartlara göre \%99'unun küçük ölçekli işletme olması işletmelerin risklere karşı duyarlılıklarının yüksek olmasına, teknolojilerin kullanılmasının zorlaşmasına, stratejik düşünmeye ve işbirliği oluşturmayı engellemektedir. Ayrıca tarım arazilerinin parçalı olması, kırsal alanlarda eğitim ve sosyal imkanların yetersiz olması, girdi maliyetlerinin yüksek olması ile kişi başına düşen gelirin diğer sektörlere göre daha düşük olması neticesinde tarım sektöründen diğer sektörlere kaynak transferini hızlandırmaktadır. Bu yapı içerisinde tüm bu bileşenlerin odak noktası ise girişimcilik olarak görülmektedir. $\mathrm{Bu}$ nedenle tarım sektörünün yapısal, ekonomik ve çevresel özellikleri göz önünde bulundurulduğunda girişimciliğin yaygınlaştırılması zorlu bir süreçtir. Tarım sektöründe bu süreçteki sorunlar makroekonomik olsa da çözüm önerileri mikroekonomiktir. Bu nedenle makro düzeydeki analizler, genel yönlendirme sağlamak için yararlı olsa da tarım işletmelerinin farklı yapıları ve heterojen özellikleri nedeniyle mikro düzeyde analizlere ihtiyaç duyulmaktadır. Bu kapsamda yapılan çalışmanın temel amacı Konya ilindeki tarım işletmelerinin girişimcilik düzeylerinin belirlenerek politika önerisinden bulunmaktır.

\section{Materyal ve Metot}

Çalışma kapsamında birincil veriler, Konya ili Ereğli içesinde tarımsal üretim faaliyeti gerçekleştiren 98 işletme ile anket yoluyla toplanan veriler olup, araştırma kullanılan ikincil veriler ise Tarım ve Orman Bakanlığı, TÜik ve FAO 
gibi istatistik kurumlarının yanı sıra konu ile ilgili ulusal ve uluslararası alanda yapılmış çalışmalar, raporlar, yayınlar ve araştırmalardan oluşmaktadır.

Araştırma bölgesi olan Konya ili Ereğli ilçesinde faaliyet gösteren tarım işletmeleri toplam popülasyonu oluşturmaktadır. Araştırmanın popülasyonu belirlenen işletmelerin arazi genişlikleri dikkate alınmış ve varyasyon katsayısının \%75 üzerinde çıkmasından dolayı tabakalı tesadüfi örnekleme yöntemi kullanılmıştır. Bu yönteme göre belirlenen 98 tarım işletmesi ile anket yapılmıştır. Örnek belirlenmesinde $\% 5$ hata payı ve $\% 90$ güven sınırları dikkate alınmış ve işletme gruplarına göre dağılımda Yamane'nin 1967 yılında kullandığı eşitlikten yararlanılmıştır (Yamane, 1967). Çalışma kapsamında 0-50 dekar arazi sahibi işletmelere küçük ölçekli, 51-150 dekar arazi sahibi işletmelere orta ölçekli ve 151-+ dekar arazi sahibi işletmelere ise büyük ölçekli işletmeler olarak tanımlanmıştır.

$$
\mathrm{n}=\frac{(\Sigma \mathrm{Nh} \cdot \mathrm{Sh})^{2}}{\mathrm{~N}^{2} \cdot \mathrm{D}^{2}+\Sigma\left(\mathrm{Nh} \cdot S h^{2}\right)} \quad \mathrm{D}^{2}=\mathrm{d}^{2} / \mathrm{z}^{2}
$$

n: Örnek sayısı,

$\mathrm{N}$ : Popülasyondaki işletme sayısı,

Nh: h'ıncı tabakadaki işletme sayısı,

Sh: h'ıncı tabakanın varyansı,

$\mathrm{d}$ : Popülasyon ortalamasından izin verilen hata payı,

z: Hata oranına göre standart normal dağııım Tablosundaki z değerini ifade etmektedir.

Çizelge 1. İşletme büyüklükleri itibariyle örnek sayısı

Table 1. Number of samples by enterprise size

\begin{tabular}{|c|c|c|c|c|c|c|c|}
\hline $\begin{array}{c}\text { Işletme büyüklüğü } \\
\text { Enterprise size } \\
\text { (decare) }\end{array}$ & $\begin{array}{c}\text { Tabakadaki işletme sayısı } \\
\text { Unit number } \\
\text { of strata (Nh) }\end{array}$ & $\begin{array}{c}\text { Tabaka varyansı } \\
\text { Standard } \\
\text { deviation }(\text { Sh) }\end{array}$ & $\begin{array}{c}\text { Ortalama } \\
\text { Mean }\end{array}$ & CV & Nh*Sh & Nh*(Sh) $^{2}$ & $\mathrm{n}$ \\
\hline $0-50$ & 2.093 & 9,99 & 32,31 & 30,91 & $20.903,55$ & $208.771,37$ & 8 \\
\hline $51-150$ & 2.845 & 28,41 & 90,94 & 31,24 & $80.821,75$ & $2.296 .012,63$ & 32 \\
\hline $151-+$ & 1.820 & 79,76 & 243,13 & 32,8 & $145.157,27$ & $11.577 .271,13$ & 58 \\
\hline Total & 6.758 & & & 246.883 & 14.082 .055 & 98 \\
\hline
\end{tabular}

Tarım işletmelerinin yapısı gereği işletme sahibi yönetici ve girişimci görevini üstlenmektedir. Ancak bu çalışma kapsamında yöneticilik bir birimin idare edilmesine verilen isim olmakla birlikte girişimci bazı özellikleri kendisinde taşıyan yöneticilere verilen sıfat olarak tanımlanmıştır. Bu nedenle tarım işletmeleri yöneticilerinin girişimcilik özelliklerini ne kadar taşıdıklarını belirlemek için girişimcilik katsayısı hesaplanmıştır. Bu katsayının hesaplanmasında girişimcinin özellikleri beş gruba ayrılmıştır (PL De Wolf \& Schoorlemmer, 2007). Çalışma alanı olan Konya ili Ereğli ilçesinde faaliyet gösteren işletmelere ait girişimcilik düzeyinin ölçülmesi amacıyla girişimcilik katsayısı hesaplanmıştır. Girişimcilik katsayısı hesaplanırken kullanılan değişkenler Çizelge 2'de verilmiştir. Buna göre girişimcilik özellikleri profesyonellik, yönetim, fırsatçılık, stratejik düşünme ve iş birliği yapabilme adı altında bileşenlerine ayrılmıştır. Çalışma kapsamında girişimcilik katsayısı 1 ile 5 arasında ölçeklendirilmiştir. Bu nedenle çalışmada kullanılan bütün değişkenler bu ölçeğe göre düzenlenmiştir.

Çalışmada nominal ve sıralı özellikteki kategorik değişkenler ile ölçülmüş değişkenler kullanılmıştır. Örneğin sigorta yapma durumu nominal veri olarak (sigorta yaptıran:1, yaptırmayan :0) anket uygulamasında elde edilmiş olup, eğitim, konferans takibi, fuara katılım, desteklemeler vb. göstergeler de sıralı özellikteki kategorik değişkenler olarak elde edilmiştir. Fakat nominal veriler, veri türleri içerisinde en az güvenilir olmaları ve bilgi taşımaları nedeniyle dolayı çalışma kapsamında nominal veriler ordinal verilere dönüştürülmüştür. $\mathrm{Bu}$ veriler dönüştürülürken likert ölçeği dikkate alınmıştır. Örneğin pinomatik ekim makinası sahip işletmelerin oranı \%42.2 olarak belirlenmiştir. Bu oran $5^{\prime}$ li likert ölçeğinde $2.11(5 \times 42.2 / 100)$ olarak 
hesaplanmıştır. Diğer bazı göstergelerde ise (deneyim, karar vermek, traktör yaşı, desteklemeler, ürün çeşitliliği) yıl, para birimi, adet ve eğitim gibi göstergeler kullanılmış olup, bu oranların ortalamasının karşılığı olarak 5'li likert ölçeği yardımıyla skorlar hesaplanmıştır.

Çizelge 2.Girişimcilik katsayısı değişkenlerine ait skorlar

Table 2. Scores of the variables of entrepreneurship coefficient

Değişkenler (Variables)

Aile bireylerinin çalışması \%

Work of family members\%

Anıza direk ekim makinası \%

Stubble direct sowing machine\%

Barınak modernizasyonu \%

Shelter modernization\%

Biyoyakıt kullanımı \% (Use of biofuels\%)

Borç /sermaye oranı \% (Debt / capital ratio\%)

Daimî işgücü çalıştırma\% (Standing workforce\%)

Deneyim (yıl) (Experience) (years)

Desteklemeler (Bin TL) (Supports (Thousand TL))

Diğer üreticilerle iş birliği \%

Collaboration with other Manufacturers\%

Eğitim (Education)

Fuara katılım ve Sıklığı (yıl)

Participation in the fair and its frequency (year)

İş bölümü ve uzmanlaşma \%

Department of business and specialization\%

İş planlaması \% (Business planning\%)

Karar verme (yıl) (Decision making (year))

Kayıt tutma \% (Record keep\%)

Konferans takibi ve sıklığı (yıl)

Conference tracking and frequency (year)

Kredi kullanma \% (Using credit\%)

Makine ve işgücünde yardımlaşma \%

Machinery and labor force\%

Ortağa ve kiraya arazi işleme \%

Land and lease land processing\%

Ortalama traktör yaşı (Average tractor age)

Öz sermaye/pasif oranı \% Equity/passive rate\%

Pinomatik ekim makinesi \% Pinomatic sowing machine\%

Sigorta yaptırma \% (Insuarence\%)

Soğuk hava deposu \% (Cold storage\%)

1
$0-20$
$0-20$
$0-20$

Sorun çözme \% (Solve problem \%)

Sözleşmeli üretim \% (Contracted production\%)

Sulama sistemleri\% (Irrigation systems\%)

Sulu arazi oranı (\%) (Aqueous land ratio (\%))

Suni tohumlama \% (Artificial insemination\%)

Teknik bilgiye dayalı girdi kullanımı \%

Technical information based input use\%

Toprak analizi yaptırma \% Soil analysis\%

Toprak işlemesiz / azaltılmış tarım \%

Non-tillage / Reduced agriculture\%

Üretim planında değişiklik yapma \%

Modifying the production plan\%

Ürün çeşitliliği (Product variety)

Ürün pazarlaması \% (Product marketing\%)

Yabancı işgücü çalıştırma \%

Foreign labor\%

Yaş (yıl) (Age (years))

Yatırım kararları ve hedefleri \%

Investment decisions and goals\%

Yazılı ve görsel yayın takibi \%

Written and visual broadcast tracking\%

Yeni tarım sistemleri \%

New agricultural systems\%

$1 \quad 2$

\begin{tabular}{|c|c|}
2 & $21-40$ \\
$21-40$
\end{tabular}

\begin{tabular}{|c|c|}
\hline 3 \\
$41-60$ \\
$41-60$ \\
\hline
\end{tabular}

\begin{tabular}{c|c}
4 & 5 \\
$61-80$ & $81-100$ \\
\hline $61-80$ & $81-100$
\end{tabular}

$0-20$

21-40

$41-60$

$61-80$

81-100

\begin{tabular}{l|l|l}
$0-20$ & $21-40$ & \\
\hline $0-20$ & $21-40$ &
\end{tabular}

41-60

10-

10-20

21-40

$41-60$

21-25

\begin{tabular}{c|c}
\hline $1-5$ & $6-10$ \\
\hline $0-20$ & $21-40$ \\
\hline Lisans & Önlisans \\
\hline 1 & 2
\end{tabular}

41-60 $61-8$

61-80

$81-100$

61-80 $81-100$

$61-80 \quad 81-100$

$61-80$

26-30

16-20

$81-100$

$0-20$

$\mid \frac{1}{2}+2$

\begin{tabular}{|c|}
\hline $0-20$ \\
\hline $0-20$ \\
\hline $10-15$ \\
\hline $0-20$
\end{tabular}

\begin{tabular}{|c|c|}
\hline $1-20$ & $21-40$ \\
\hline $0-20$ & 21-40 \\
\hline
\end{tabular}

$10-15$
$0-20$
1

\begin{tabular}{c|c|c}
$0-20-15$ & $16-20$ & \\
\hline $0-20$ & $21-40$ & 41 \\
\hline
\end{tabular}

41-60

\begin{tabular}{|c|c|c|}
\hline $0-20$ & $21-40$ & $41-60$ \\
\hline $0-20$ & $21-40$ & $41-60$ \\
\hline $0-5$ & $6-10$ & $11-15$ \\
\hline $0-20$ & $21-40$ & $41-60$ \\
\hline $0-20$ & $21-40$ & $41-60$ \\
\hline $0-20$ & $21-40$ & $41-60$ \\
\hline $0-20$ & $21-40$ & $41-60$ \\
\hline
\end{tabular}

\begin{tabular}{|c|c|c|}
\hline $0-20$ & $21-40$ & $41-60$ \\
\hline $0-20$ & $21-40$ & $41-60$ \\
\hline $0-20$ & $21-40$ & $41-60$ \\
\hline $0-20$ & $21-40$ & $41-60$ \\
\hline $0-20$ & $21-40$ & $41-60$
\end{tabular}

$0-20$

$0-20$

$0-20 \quad 21-40$

\begin{tabular}{|c|}
\hline $41-60$ \\
$41-60$ \\
\hline $41-60$
\end{tabular}

\begin{tabular}{|c|c|}
\hline $0-20$ & $21-40$ \\
\hline $0-20$ & $21-40$ \\
\hline $0-20$ & $21-40$ \\
\hline $0-20$ & $21-40$ \\
\hline $1-2$ & $3-4$ \\
\hline $0-20$ & $21-40$ \\
\hline $0-20$ & $21-40$ \\
\hline $20-30$ & $31-40$ \\
\hline $0-20$ & $21-40$ \\
\hline $0-20$ & $21-40$ \\
\hline $0-5$ & $6-10$ \\
\hline
\end{tabular}

\begin{tabular}{|c|c|}
\hline $41-60$ & $41-60$ \\
\hline $41-60$ & \\
$41-60$ & 6 \\
\hline $41-60$ & $6-6$ \\
\hline $41-60$ & \\
\hline $41-60$ & \\
\hline $41-50$ & \\
\hline $41-60$ & \\
\hline $41-60$ & 6 \\
\hline $11-15$ & \\
\hline
\end{tabular}

$61-80$

81-100

Kaynak: Bayramoğlu, Karakayacı, and Candemir (2013) 


\section{Bulgular ve Tartışma}

Tarımsal girişimci, kabul edilebilir risk düzeyinde fırsatları algılayan ve onları harekete geçiren, yenilikçi bir kişiliğe sahip olan ve üretim faktörlerinin organizasyonunu sağlayıp işletmedeki her türlü karı ve zararı üstlenen kişi olarak tanımlanmaktadır. Bu nedenle üretim faktörlerine girişimcilik dahil edilmiştir. Özellikle üretim faktörlerinin kullanımı ve organizasyondaki başarısı işletmenin başarısını artırmasından dolayı girişimcilik daha da önemli hale gelmiştir. Örneğin aynı üretim faktörlerine ve teknik koşullara sahip olan 2 işletmenin birbirlerinden gelirlerinin farklı olmasının temelinde sahip oldukları girişimcilik ve dolayısıyla işletmecilik farklııkları yer almaktadır. $\mathrm{Bu}$ kapsamda üretim faktörlerinin niteliksel öneminin niceliksel olarak ifade edilmesi mümkün olurken, girişimcilik yeteneğini ölçmek, diğerlerine göre daha zordur. Bu nedenle araştırma bölgesinde yer alan tarım işletmelerinin girişimcilik düzeylerinin belirlenmesine yönelik sosyo-ekonomik değişkenler belirlenmiş ve bu yönde işletmelerin girişimcilik katsayıları hesaplanmıştır. Girişimcilik katsayını hesaplarken ilk belirlenen kriter "profesyonellik" özelliğidir. Profesyonellik, birçok değişik tanımla birlikte üretim faaliyetlerinde kar elde etmek amacıyla kaynakların rasyonel olarak kullanılarak bir işin yapılmasına denilmektedir (Bayramoğlu et al., 2013). Tanımdan yola çıkarak rasyonellik üretim faktörlerini en uygun şekilde kullanılmasını ifade ettiği gibi bu durum girişimciliğinde aynı zamanda temelini oluşturmaktadır. Rasyonel davranabilmek sadece ekonomik olarak değil aynı zamanda sosyal olarak da ortaya çıkmaktadır. Nitekim tarım işletmeleri incelenirken sadece ekonomik değil aynı zamanda sosyo-ekonomik analizleri bir bütün olarak değerlendirilmektedir. Sosyo-ekonomik analizlerle birlikte üreticilerin psikolojik özelliklerinde ekonomik faaliyetlere etkisi olduğu bilinmektedir. Bu anlamda üreticiler üzerinde profesyonellik kavramı hem ekonomik hem de sosyal bir olgu olarak incelenmelidir.

Çizelge 3. İşletme büyüklüklerine göre profesyonel tecrübe skorları

Table 3. Professional experience scores by enterprise size

\begin{tabular}{|c|c|c|c|c|c|c|}
\hline \multirow[b]{2}{*}{$\begin{array}{l}\text { Kategoriler } \\
\text { (Category) }\end{array}$} & \multirow[b]{2}{*}{$\begin{array}{l}\text { Değişkenler } \\
\text { (Variables) }\end{array}$} & \multirow[b]{2}{*}{$\begin{array}{l}\text { Göstergeler } \\
\text { (Indicators) }\end{array}$} & \multicolumn{4}{|c|}{$\begin{array}{l}\text { İşletme büyüklüğü (dekar) } \\
\text { Enterprise size (decare) }\end{array}$} \\
\hline & & & $0-50$ & $51-150$ & 151-+ & $\begin{array}{l}\text { İşletmeler } \\
\text { ortalaması } \\
\text { (Average of } \\
\text { enterprises) }\end{array}$ \\
\hline \multirow{11}{*}{$\begin{array}{l}\text { Profesyonel } \\
\text { tecrübe } \\
\text { (Professional } \\
\text { experience) }\end{array}$} & \multirow{4}{*}{$\begin{array}{l}\text { Bitkisel ve } \\
\text { hayvansal } \\
\text { üretim becerisi } \\
\text { (Plan or animal } \\
\text { production } \\
\text { skills) }\end{array}$} & Deneyim (Experience) & 3.95 & 4.18 & 4.75 & 4.50 \\
\hline & & Karar verme (To decide) & 4.23 & 4.55 & 4.90 & 4.73 \\
\hline & & Kayıt tutma (Record keeping) & 1.80 & 2.73 & 3.25 & 2.96 \\
\hline & & $\begin{array}{l}\text { Değişken ortalaması } \\
\text { (Variable averages) }\end{array}$ & 3.33 & 3.82 & 4.30 & 4.06 \\
\hline & \multirow{6}{*}{$\begin{array}{l}\text { Teknik beceri } \\
\text { (Technical skills) }\end{array}$} & Yaş (Age) & 3.95 & 3.52 & 3.28 & 3.41 \\
\hline & & Eğitim (Education) & 2.18 & 2.79 & 3.68 & 3.27 \\
\hline & & Kredi kullanma (Using credits) & 4.19 & 4.07 & 4.42 & 4.29 \\
\hline & & $\begin{array}{l}\text { Teknik bilgiye dayalı girdi kullanımı } \\
\text { (Technical information based input } \\
\text { usage) }\end{array}$ & 3.76 & 4.14 & 4.46 & 4.30 \\
\hline & & $\begin{array}{l}\text { Toprak analizi yaptırma } \\
\text { (Soil analysis) }\end{array}$ & 3.75 & 3.92 & 4.27 & 4.11 \\
\hline & & $\begin{array}{l}\text { Değişken ortalaması } \\
\text { (Variable averages) }\end{array}$ & 3.57 & 3.69 & 4.02 & 3.88 \\
\hline & \multicolumn{2}{|c|}{$\begin{array}{l}\text { Kategori ortalaması } \\
\text { (Category average) }\end{array}$} & 3.45 & 3.75 & 4.16 & 3.97 \\
\hline
\end{tabular}

Tarımsal girişimcilerin profesyonellik katsayını belirlemek için bitkisel ve hayvansal üretim becerilerinin yanı sıra teknik becerilerini de ifade eden sorular yönlendirilmiştir (Çizelge 3). Bitkisel ve hayvansal üretim becerisinin skoru işletmeler ortalamasına göre 4.06 olarak belirlenmiştir. Bu değer işletmeler ölçeğine göre farklılık arz etmekle birlikte işletme ölçeği büyüdükçe bitkisel ve hayvansal üretim becerisinin yükseldiği görülmektedir. Nitekim tarım işletmelerinde 
üretim becerisini etkileyen faktörler olarak deneyim, karar verme ve kayıt tutma esas olarak alınmaktadır. Bu göstergeler işletme ölçeğinin büyümesine paralel olarak arttığı görülmüştür. Incelenen işletmelerde teknik beceri ise yaş, eğitim, kredi kullanma, teknik bilgiye dayalı girdi kullanımı ve toprak analizi yaptırma değişkenleriyle ölçülmüştür. Incelenen işletmelerde teknik beceri skoru işletmeler ortalamasına göre 3.88 olarak hesaplanmıştır. Bu skor işletme ölçeğinin büyümesine paralel olarak arttığı görülmektedir. Tarım işletmelerinin ölçeğinin büyümesiyle birlikte yaş ortalamasının düştüğü ve eğitim düzeyinin arttığı anket sonuçlarından görülmektedir. Ayrıca büyük işletmelerin riski daha fazla almasına paralel olarak kredi kullanımı daha yüksek olmaktadır. Bu işletmelerde birim alandan veya birim hayvandan daha verim alınmasında da teknik bilgi kullanımının etkisinin olduğu belirlenmiştir. Büyük ölçekli işletmelerde diğer işletmelere göre toprak analizi yaptırma oranı daha yüksek olarak tespit edilmiş olup bu işletme grubundaki üreticilerin kaynakları daha etkin ve verimli kullandıkları görülmektedir. Girişimcilik katsayısının belirlenmesinde ilk adım olan profesyonellik bileşeninin genel ortalaması ise işletme ortalamasına göre 3.97 skor olarak belirlenmiştir. Analizler sonucunda büyük ölçekli işletmelerin diğer işletmelere göre daha profesyonel davrandıkları görülmüş olup, işletmelerin girişimci olmasında bu kriterin payı yüksektir.

Tarım sektöründe profesyonellik, bir yatırım konusunu kendine meslek olarak seçen, bu konuda derinleşerek o alandaki bilgi ve deneyimiyle hayatını kazanan kişidir (Morgül \& Ayan, 2013). Özellikle tarım sektörünün cazibeli bir meslek hale gelmesinde profesyonelliğin önemi son derece yüksektir. Nitekim profesyonellik, tarım sektöründeki mesleki standartların belirlenmesi açısından ve üretim faaliyetlerinde kalite, verim ve karlılığın yükselmesinde temel nitelikler arasında yer almaktadır. Profesyonelliğin sürdürülebilir olarak sağlanması için ise mesleğin bilimsel ve teknik yönleri çerçevesinde araştırmacı olabilme, yenilikçi, risk alabilen, otonom ve öğrenmeye açık bulunma özelliklerine sahip olunması gereklidir. $\mathrm{Bu}$ sayede tarım sektöründe profesyonelliğin kazanılmasıyla birlikte işletme ve topluma sağlanan fayda maksimize edilmiş olacaktır. (Pieter De Wolf, Schoorlemmer, \& Rudmann, 2007; McElwee, 2005; J Pyysiäinen \& Vesala, 2007).

Girişimcilik katsayını belirlemede kullanılan ikinci özellik ise "yönetim"dir (Çizelge 4). Tarım işletmelerinde yönetim ise, temel amaçları doğrultusunda işletme içi veya işletmeler arası iş birliği yapmak, işletme içinde görev dağılımı yaparak hedefler doğrultusunda çalışmaktır. Tarım işletmelerinde ailenin yaşam alanı ile çiftlik bütünleşmiş durumdadır. Nitekim tarım işletmelerinde yönetici ile işçi aynı kişiden oluşmaktadır. Bu durum tarım işletmelerini yönetim açısından diğer işletmelere göre farklılık göstermesine neden olmaktadır. Fakat tarım işletmelerinde de yönetim fonksiyonuna ihtiyaç duyulmakta olup, gerekli zamanlarda müdahale edilmesi gerekmektedir. Bu nedenle tarım işletmelerinde yönetim tecrübesini etkileyen değişkenler olarak; "Finansal Yönetim Becerisi", "Insan Kaynakları Yönetim Becerisi" ve "Genel Planlama Becerisi" olarak belirlenmiştir.

Yönetim Becerisinin genel ortalamasının skoru 3.96 olarak belirlenmiştir. Nitekim daha önce bölgede yapılan çalışmalardan daha yüksek bir skor hesaplanmıştır. Bu durum Ereğli ilçesindeki girişimcilerin yönetim faaliyetleri bakımından daha tecrübeli olduklarını ve kaynakları daha etkin kullandıklarını göstermektedir(Bayramoğlu et al., 2013). Tarım işletmelerinde yönetim, kıt kaynakların bir araya getirilerek etkin kullanılması tekniği olarak ifade edilmektedir. Bu nedenle işletme yöneticisinin başarısı kıt kaynakları kullanma etkinliğine bağııdır. Özellikle literatürde yöneticilik özelliklerinin doğuştan geldiğine yönelik yanlış algılar olsa da yöneticilik sonradan eğitimlerle öğrenebilecek bir olgudur. Bu kapsamda işletmedeki ürünler hakkında teknik bilgi, iyi bir iletişim kurma, motivasyon sağlama, yönetim tekniklerine sahip olma ve yeteneklerini ortaya çıkaracak eğitim faaliyetlerinin düzenlenmesi yönetim becerisinin geliştirilmesinde son derece önemlidir. 
Çizelge 4. İşletme büyüklüklerine göre yönetim tecrübe skorları

Table 4. Management experience scores by enterprise size

\begin{tabular}{|c|c|c|c|c|c|c|}
\hline \multirow[b]{2}{*}{$\begin{array}{l}\text { Kategoriler } \\
\text { Category }\end{array}$} & \multirow[b]{2}{*}{$\begin{array}{l}\text { Değişkenler } \\
\text { Variables }\end{array}$} & \multirow[b]{2}{*}{$\begin{array}{l}\text { Göstergeler } \\
\text { Indicators }\end{array}$} & \multicolumn{4}{|c|}{$\begin{array}{l}\text { İşletme büyüklüğü (dekar) } \\
\text { Enterprise size(decare) }\end{array}$} \\
\hline & & & $0-50$ & $51-150$ & $151-+$ & $\begin{array}{l}\text { İşletmeler } \\
\text { ortalaması } \\
\text { Average of } \\
\text { enterprises } \\
\end{array}$ \\
\hline \multirow{14}{*}{$\begin{array}{l}\text { Yönetim } \\
\text { tecrübesi } \\
\text { (Management } \\
\text { experience) }\end{array}$} & \multirow{4}{*}{$\begin{array}{l}\text { Finansal } \\
\text { yönetim becerisi } \\
\text { (Financial } \\
\text { management } \\
\text { skills) }\end{array}$} & $\begin{array}{l}\text { Borç /sermaye oranı \% } \\
\text { (Debt / capital ratio\%) }\end{array}$ & 4.18 & 4.32 & 4.56 & 4.45 \\
\hline & & $\begin{array}{l}\text { Kredi kullanma } \\
\text { (Using credits) }\end{array}$ & 4.19 & 4.07 & 4.42 & 4.29 \\
\hline & & $\begin{array}{l}\text { Desteklemeler (Bin TL) } \\
\text { (Supports(Thousand TL)) }\end{array}$ & 4.70 & 4.79 & 4.95 & 4.88 \\
\hline & & $\begin{array}{l}\text { Değişken ortalaması } \\
\text { (Variable averages) }\end{array}$ & 4.36 & 4.39 & 4.64 & 4.54 \\
\hline & \multirow{6}{*}{$\begin{array}{l}\text { İnsan kaynakları } \\
\text { yönetim becerisi } \\
\text { (Human } \\
\text { resource } \\
\text { management } \\
\text { skills) }\end{array}$} & Yaş (Age) & 3.95 & 3.52 & 3.28 & 3.41 \\
\hline & & Eğitim (Education) & 2.18 & 2.79 & 3.68 & 3.27 \\
\hline & & $\begin{array}{l}\text { Aile bireylerinin çalışması } \\
\text { (Study of family members) }\end{array}$ & 4.20 & 4.17 & 3.95 & 4.04 \\
\hline & & $\begin{array}{l}\text { Yabancı işgücü çalıştırma } \\
\text { Foreign labor }\end{array}$ & 2.20 & 2.90 & 3.49 & 3.19 \\
\hline & & $\begin{array}{l}\text { Daimî işgücü çalıştırma } \\
\text { (Permanent workforce) }\end{array}$ & 1.43 & 2.95 & 4.25 & 3.60 \\
\hline & & $\begin{array}{l}\text { Değişken ortalaması } \\
\text { (Variable averages) }\end{array}$ & 2.79 & 3.27 & 3.73 & 3.50 \\
\hline & \multirow{3}{*}{$\begin{array}{l}\text { Genel Planlama } \\
\text { Becerisi } \\
\text { (General } \\
\text { Planning Skills) }\end{array}$} & $\begin{array}{l}\text { Kayıt tutma } \\
\text { (Record keeping) }\end{array}$ & 1.80 & 2.73 & 3.25 & 2.96 \\
\hline & & $\begin{array}{l}\text { Karar verme } \\
\text { (To decide) }\end{array}$ & 4.23 & 4.55 & 4.90 & 4.73 \\
\hline & & $\begin{array}{l}\text { Değişken ortalaması } \\
\text { (Variable averages) }\end{array}$ & 3.02 & 3.64 & 4.08 & 3.85 \\
\hline & \multicolumn{2}{|c|}{$\begin{array}{l}\text { Kategori ortalaması } \\
\text { Category average }\end{array}$} & 3.39 & 3.77 & 4.15 & 3.96 \\
\hline
\end{tabular}

Girişimciliğin katsayını belirlemede kullanılan bir diğer kategori ise "fırsat tecrübesi"dir. Fırsat tecrübesi ise iş fırsatlarının farkındalığı, tehditlerin farkındalığı, yenilikçilik ve risk yönetim becerisi olarak alt bileşenlerden oluşmaktadır. İş fırsatların farkındalığının skoru işletmeler ortalamasına göre 3.48 olarak belirlenmiştir (Çizelge 5). Tarımda özellikle toprak işlemesiz veya azaltılmış toprak işleme, organik veya iyi tarım ile üretim planında değişiklik yaparak tarımda fırsatlardan yararlanmak girişimciliğin bir getirisidir. Bu anlamda işletme ölçeklerine göre bu göstergelerin skorları yükselmekte olup büyük işletmelerin tarımdaki fırsatlara karşı farkındalıklarının yüksek olduğu tespit edilmiştir.

Tarımsal üretim risk ve belirsizliklerin yoğun olduğu bir faaliyettir. Bu anlamda üretimde birçok tehditin olması girişimciliği etkilemektedir. Girişimciler oluşan bu tehditlere karşı bir dizi önlemler alması gerekir ki işletmeler ancak bu durumda sürdürülebilir olabilmektedir. Bu kapsamda üretici yaşı ve deneyim, oluşan bu tehditlere karşı farkındalık açısından önemlidir. Ayrıca sözleşmeli üretim yapılması, risklere karşı sigorta yapılması veya ürün çeşitliliğin sağlanması ile riskin paylaştırılması gibi önlemler alınarak tehditlere karşı farkındalık oluşturulmaktadır. Girişimcilerin oluşan tehditlere karşı farkındalığının skoru 3.74 olarak belirlenmiştir. Fırsat tecrübesinin bir diğer bileşeni olan risk yönetim becerisi incelenen işletmelerde 3.89 olarak hesaplanmıştır. Sonuçlara göre büyük ölçekli işletmelerin risk yönetim becerilerinin daha yüksek olduğu belirlenmiştir. Çünkü büyük ölçekli işletmelerde sigorta yaptırma oranı ve risk algısı daha yüksektir. Ayrıca bu işletmelerde üretim çeşitliliğinin sağlanmasında risklerin paylaşılması açısından önemlidir. 
Çizelge 5. İşletme büyüklüklerine göre fırsat tecrübe skorları Table 5. Opportunity experience scores by enterprise size

\begin{tabular}{|c|c|c|c|c|c|c|}
\hline \multirow{2}{*}{$\begin{array}{c}\text { Kategoriler } \\
\text { Category }\end{array}$} & \multirow[b]{2}{*}{$\begin{array}{c}\text { Değişkenler } \\
\text { Variables }\end{array}$} & \multirow[b]{2}{*}{$\begin{array}{l}\text { Göstergeler } \\
\text { Indicators }\end{array}$} & \multicolumn{4}{|c|}{$\begin{array}{l}\text { İşletme büyüklüğü (dekar) } \\
\text { Enterprise size(decare) }\end{array}$} \\
\hline & & & $0-50$ & $51-150$ & 151-+ & $\begin{array}{l}\text { Işletmeler } \\
\text { ortalaması } \\
\text { Average of } \\
\text { enterprises }\end{array}$ \\
\hline \multirow{32}{*}{$\begin{array}{l}\text { Fırsat } \\
\text { tecrübesi } \\
\text { Opportunity } \\
\text { experience }\end{array}$} & \multirow{4}{*}{$\begin{array}{l}\text { İş fırsatlarının } \\
\text { farkındalığı } \\
\text { Recognising } \\
\text { business } \\
\text { opportunity }\end{array}$} & $\begin{array}{l}\text { Toprak işlemesiz/ azaltılmıs Tarım } \\
\text { Soil-free / reduced agriculture }\end{array}$ & 2.15 & 3.24 & 3.78 & 3.47 \\
\hline & & $\begin{array}{l}\text { Organik veya iyi tarım yapma } \\
\text { Organic or good farming }\end{array}$ & 3.92 & 4.18 & 4.56 & 4.38 \\
\hline & & $\begin{array}{l}\text { Üretim planında değişiklik yapma } \\
\text { Modifying the production plan }\end{array}$ & 2.00 & 2.00 & 3.00 & 2.59 \\
\hline & & $\begin{array}{l}\text { Değişken ortalaması } \\
\text { Variable averages }\end{array}$ & 2.69 & 3.14 & 3.78 & 3.48 \\
\hline & \multirow{7}{*}{$\begin{array}{l}\text { Tehditlerin } \\
\text { farkındalığı } \\
\text { Awareness of } \\
\text { threats }\end{array}$} & Yaş (Age) & 3.95 & 3.52 & 3.28 & 3.41 \\
\hline & & $\begin{array}{l}\text { Deneyim } \\
\text { Experience }\end{array}$ & 3.23 & 3.15 & 3.89 & 3.59 \\
\hline & & $\begin{array}{l}\text { Üretim planında değişiklik yapma } \\
\text { Modifying the production plan }\end{array}$ & 2.46 & 3.75 & 4.34 & 3.99 \\
\hline & & $\begin{array}{l}\text { Sözleşmeli üretim } \\
\text { Contract manufacturing }\end{array}$ & 2.96 & 3.59 & 4.24 & 3.92 \\
\hline & & $\begin{array}{l}\text { Sigorta yaptırma } \\
\text { Insurance }\end{array}$ & 1.78 & 3.14 & 3.93 & 3.50 \\
\hline & & $\begin{array}{l}\text { Ürün çeşitliliği } \\
\text { Product variety }\end{array}$ & 2.75 & 3.82 & 4.26 & 3.99 \\
\hline & & $\begin{array}{l}\text { Değişken ortalaması } \\
\text { Variable averages }\end{array}$ & 2.86 & 3.5 & 3.99 & 3.74 \\
\hline & \multirow{13}{*}{$\begin{array}{l}\text { Yenilikçilik } \\
\text { Innovation skills }\end{array}$} & Yaş (Age) & 3.95 & 3.52 & 3.28 & 3.41 \\
\hline & & Eğitim (Education) & 3.23 & 3.15 & 3.89 & 3.59 \\
\hline & & $\begin{array}{l}\text { Toprak işlemesiz/ azaltılmış tarım } \\
\text { Soil-free / reduced agriculture }\end{array}$ & 2.15 & 3.24 & 3.78 & 3.47 \\
\hline & & $\begin{array}{l}\text { Sulama sistemleri } \\
\text { Irrigation systems }\end{array}$ & 3.42 & 3.98 & 4.46 & 4.22 \\
\hline & & $\begin{array}{l}\text { Ortalama traktör yaşı } \\
\text { Average tractor age }\end{array}$ & 1.86 & 2.95 & 3.78 & 3.35 \\
\hline & & $\begin{array}{l}\text { Barınak modernizasyonu \% } \\
\text { Shelter modernization }\end{array}$ & 2.95 & 3.49 & 4.21 & 3.87 \\
\hline & & $\begin{array}{l}\text { Suni tohumlama } \\
\text { Artificial insemination }\end{array}$ & 4.49 & 4.82 & 4.95 & 4.87 \\
\hline & & $\begin{array}{l}\text { Soğuk hava deposu } \\
\text { Cold storage }\end{array}$ & 1.75 & 2.23 & 2.85 & 2.56 \\
\hline & & $\begin{array}{l}\text { Biyoyakıt kullanımı } \\
\text { Use of biofuels }\end{array}$ & 1.05 & 1.85 & 2.23 & 2.01 \\
\hline & & $\begin{array}{l}\text { Pinomatik ekim makinesi } \\
\text { Pinomatic sowing machine }\end{array}$ & 2.85 & 3.26 & 3.73 & 3.50 \\
\hline & & $\begin{array}{l}\text { Anıza direk ekim makinası } \\
\text { Stubble direct sowing machine }\end{array}$ & 1.42 & 1.89 & 2.32 & 2.11 \\
\hline & & $\begin{array}{l}\text { Yeni tarım sistemleri \% } \\
\text { New agricultural systems }\end{array}$ & 1.76 & 2.18 & 2.95 & 2.6 \\
\hline & & $\begin{array}{l}\text { Değişken ortalaması } \\
\text { Variable averages }\end{array}$ & 2.57 & 3.05 & 3.54 & 3.3 \\
\hline & \multirow{7}{*}{$\begin{array}{l}\text { Risk yönetim } \\
\text { becerisi } \\
\text { Risk } \\
\text { management } \\
\text { skills }\end{array}$} & Yaş (Age) & 3.95 & 3.52 & 3.28 & 3.41 \\
\hline & & Deneyim (Experience) & 3.23 & 3.15 & 3.89 & 3.59 \\
\hline & & Karar verme (To decide) & 4.23 & 4.55 & 4.9 & 4.73 \\
\hline & & $\begin{array}{l}\text { Sigorta yaptırma } \\
\text { Insurance }\end{array}$ & 1.78 & 3.14 & 3.93 & 3.50 \\
\hline & & $\begin{array}{l}\text { Toprak analizi yaptırma } \\
\text { Soil analysis }\end{array}$ & 3.75 & 3.92 & 4.27 & 4.11 \\
\hline & & $\begin{array}{l}\text { Ürün çeşitliliği } \\
\text { Product variety }\end{array}$ & 2.75 & 3.82 & 4.26 & 3.99 \\
\hline & & $\begin{array}{l}\text { Değişken ortalaması } \\
\text { Variable averages }\end{array}$ & 3.28 & 3.68 & 4.09 & 3.89 \\
\hline & \multicolumn{2}{|c|}{$\begin{array}{l}\text { Kategori ortalaması } \\
\text { Category average }\end{array}$} & 2.85 & 3.34 & 3.85 & 3.60 \\
\hline
\end{tabular}


Çizelge 6. İşletme büyüklüklerine göre stratejik tecrübe skorları

Table 6. Strategic experience scores by enterprise size

\begin{tabular}{|c|c|c|c|c|c|c|}
\hline \multirow[b]{2}{*}{$\begin{array}{l}\text { Kategoriler } \\
\text { Category }\end{array}$} & \multirow[b]{2}{*}{$\begin{array}{l}\text { Değişkenler } \\
\text { Variables }\end{array}$} & \multirow[b]{2}{*}{$\begin{array}{l}\text { Göstergeler } \\
\text { Indicators }\end{array}$} & \multicolumn{4}{|c|}{$\begin{array}{l}\text { İşletme büyüklüğü (dekar) } \\
\text { Enterprise size(decare) }\end{array}$} \\
\hline & & & $0-50$ & $51-150$ & 151-+ & $\begin{array}{l}\text { İşletmeler } \\
\text { ortalaması } \\
\text { Average of } \\
\text { enterprises }\end{array}$ \\
\hline \multirow{20}{*}{$\begin{array}{l}\text { Stratejik } \\
\text { tecrübe } \\
\text { Strategic } \\
\text { experience }\end{array}$} & \multirow{6}{*}{$\begin{array}{l}\text { İzleme ve } \\
\text { değerlendirme } \\
\text { becerisi } \\
\text { Monitoring and } \\
\text { evaluation skills }\end{array}$} & Yaş (Age) & 3.95 & 3.52 & 3.28 & 3.41 \\
\hline & & Eğitim (Education) & 3.23 & 3.15 & 3.89 & 3.59 \\
\hline & & $\begin{array}{l}\text { Konferans takibi ve sıklığı } \\
\text { Conference tracking and frequency }\end{array}$ & 2.86 & 2.95 & 3.11 & 3.04 \\
\hline & & $\begin{array}{l}\text { Fuara katılım ve sıklığı } \\
\text { Participation in the fair and its frequency }\end{array}$ & 3.95 & 4.33 & 4.78 & 4.57 \\
\hline & & $\begin{array}{l}\text { Yazılı ve görsel yayın takibi } \\
\text { Written and visual broadcast tracking }\end{array}$ & 2.45 & 3.52 & 4.18 & 3.82 \\
\hline & & $\begin{array}{l}\text { Değişken ortalaması } \\
\text { Variable averages }\end{array}$ & 3.29 & 3.49 & 3.85 & 3.69 \\
\hline & \multirow{7}{*}{$\begin{array}{l}\text { Stratejik karar } \\
\text { alma ve planlama } \\
\text { becerisi } \\
\text { Strategic decision } \\
\text { making and } \\
\text { planning skills }\end{array}$} & Yaş (Age) & 3.95 & 3.52 & 3.28 & 3.41 \\
\hline & & Karar verme (To decide) & 4.23 & 4.55 & 4.90 & 4.73 \\
\hline & & $\begin{array}{l}\text { Toprak işlemesiz/ azaltılmış tarım } \\
\text { Soil-free / reduced agriculture }\end{array}$ & 2.15 & 3.24 & 3.78 & 3.47 \\
\hline & & $\begin{array}{l}\text { Biyoyakıt kullanımı } \\
\text { Use of biofuels }\end{array}$ & 1.05 & 1.85 & 2.23 & 2.01 \\
\hline & & $\begin{array}{l}\text { Toprak analizi yaptırma } \\
\text { Soil analysis }\end{array}$ & 3.75 & 3.92 & 4.27 & 4.11 \\
\hline & & $\begin{array}{l}\text { Üretim planında değişiklik yapma } \\
\text { Modifying the production plan }\end{array}$ & 2.46 & 3.75 & 4.34 & 3.99 \\
\hline & & $\begin{array}{l}\text { Değişken ortalaması } \\
\text { Variable averages }\end{array}$ & 2.93 & 3.47 & 3.80 & 3.62 \\
\hline & \multirow{6}{*}{$\begin{array}{l}\text { Hedef belirleme } \\
\text { becerisi } \\
\text { Goal setting skills }\end{array}$} & $\begin{array}{l}\text { Karar verme } \\
\text { To decide }\end{array}$ & 4.23 & 4.55 & 4.90 & 4.73 \\
\hline & & Eğitim (Education) & 3.23 & 3.15 & 3.89 & 3.59 \\
\hline & & Kayıt tutma (Record keeping) & 1.80 & 2.73 & 3.25 & 2.96 \\
\hline & & $\begin{array}{l}\text { Ürün pazarlaması } \\
\text { Product marketing }\end{array}$ & 3.56 & 4.18 & 4.49 & 4.31 \\
\hline & & $\begin{array}{l}\text { Yatırım kararları ve hedefleri } \\
\text { Investment decisions and targets }\end{array}$ & 2.42 & 3.18 & 3.95 & 3.57 \\
\hline & & $\begin{array}{l}\text { Değişken ortalaması } \\
\text { Variable averages }\end{array}$ & 3.05 & 3.56 & 4.10 & 3.83 \\
\hline & \multicolumn{2}{|c|}{$\begin{array}{l}\text { Kategori ortalaması } \\
\text { Category average }\end{array}$} & 3.09 & 3.51 & 3.91 & 3.71 \\
\hline
\end{tabular}

Fırsat tecrübesini oluşturan bir diğer bileşen ise yenilikçiliktir. Yenilikçilik, girişimciliği oluşturan en önemli faktörlerden birisidir. Girişimci kişinin yenilikleri benimseme gücü daima yüksek olmalıdır. Girişimci kişi de yenilikçi olmayı etkileyen bazı göstergeler vardır. Bu göstergeler Çizelge 5'te gösterilmekte olup yenilikçiliğin işletmeler ortalamasının skoru 3.30 olarak belirlenmiştir. Özellikle incelenen küçük ölçekli işletmelerde pinomatik ekim makinası, anıza direk ekim makinası ve soğuk hava deposu gibi yenilikçi üretim faaliyetlerinin kullanılamaması skoru etkilemektedir.

Genel ortalama itibariyle fırsat tecrübesinin skoru 3.60 olarak tespit edilmiştir. Bu oran küçük ölçekli işletmelerde 3.28 skor, orta ölçekli işletmelerde 3.34 skor ve büyük ölçekli işletmelerde 3.85 skor olarak belirlenmiştir. Tarım işletmelerinde özellikle girişimcilik fırsatları, olasılıkları ve olayları iyi değerlendirmek ile ortaya çıkmaktadır. Girişimcilerin sektördeki fırsatları fark edebilmesi için ekosistem içerisinde yer alan tüm aktörler ile iletişim halinde olması gerekmektedir. Nitekim fırsatlarının doğru anlaşılması işletmenin geleceği açısından son derece önemlidir. Bunun yanı sıra sektördeki teknolojik eğilimler, rekabet seviyesi ve yasal düzenlemeler yeni fırsatları ortaya 
çıkarabilmektedir. $\mathrm{Bu}$ nedenle de tarım sektöründe girişimcilerin öncelikle sektördeki fırsatları değerlendirecek bir analize intiyaç duymaktadır. Buradaki analiz daha çok üretilecek ürünlerin tanımlanması, iş planının yapılması, fırsatların gerçeğe dönüştürülmesi ve gerekli olan finansman kaynaklarının belirlenmesini içermektedir.

Girişimciliğin dördüncü özelliği "stratejik tecrübe" olarak belirlenmiştir. Bu özellik izleme ve değerlendirme, stratejik karar alma ile planlama ve hedef belirleme olarak üç değişken olarak incelenmiştir (Çizelge 6).

İzleme ve değerlendirme değişkeni içerisinde işletmelerin tarımdaki yeniliklerin ve değişikliklerin takip edilebilmesi ve bunu etkileyen değişkenler dikkate alınmıştır. Tarımsal girişimcilerin yenilikleri takip etme en önemli kaynaklar fuar, konferans veya tarla günleri gibi etkinliklerdir. Bu nedenle bu etkinliklerin takip edilmesi girişimciliği artıran önemli faktörlerdir. $\mathrm{Bu}$ kapsamda izleme ve değerlendirme değişkeninin skoru 3.69 olup, bu durum işletme ölçeklerine artış göstermektedir. Stratejik tecrübe kategorisinin altında yer alan bir diğer değişken ise stratejik karar almadır. Tarım işletmelerinde stratejik karar alma becerisinin belirlemeye yönelik farklı göstergeler kullanılmış olup, tarım sektöründe yenilikleri kullanan işletmelerin girişimci oldukları belirlenmiştir. Nitekim toprak işlemesiz veya azaltılmış toprak işleme yöntemini kullanan işletmelerle birlikte biyoyakıt kullanan işletmelerin yenilikçi oldukları ifade edilmektedir. Ayrıca karar alma becerisinin belirlenmesi en önemli 2 gösterge, toprak analizi yaptırma ve üretim planında değişiklik yapma olup, bu yöntemlerin işletmelerde girişimcilik düzeyini arttırdığı görülmüştür.

Tarım işletmelerinde sürdürülebilirliğin sağlanmasında işbirliği son derece önemlidir. Bu nedenle girişimcilik için belirlenen diğer bir kategori ise "işbirliği tecrübesi"dir. Tarım işletmelerinde işbirliğinin ölçülmesinde 3 farklı ölçek kullanılmış olup, bunlar; "Diğer Üreticilerle İşbirliği Becerisi", "Takım Çalışması Becerisi", "Liderlik Becerisi"dir. Tarım işletmelerinin sermayelerinin yeterli olmaması işletmeler arası işbirliğinin oluşturulmasını gerektirirken, tarım işletmelerinde sahip olunan özellikle alet ekipmanları sosyal statü olarak değerlendirilmesi bu durumu engellemektedir. Oysa ki, tarım işletmeleri arasında ortağa ve kiraya tutulan arazi miktarı ile birlikte ortak makine kullanımının yaygınlaştırılması işbirliği kültürünün oluşması sosyal sermaye açısından da önemlidir. Bunun yanı sıra işletme ölçeklerinin küçük olmasına bağlı olarak, üretim faaliyetlerini gerçekleştirirken daha planlı ve uzmanlaşmaya yönelik üretim yapılması sürdürülebilirlik açısından önemlidir. Çünkü, işletme yöneticilerinin rasyonel karar almasından en önemli faktör planlama ve uzmanlaşma olup, işletme içerisinde ancak doğru ve gerçek bilgiler ile üretim faaliyetleri planlanmaktadır. Bu nedenle de tarım işletmelerinde muhasebe bilgi sistemlerinin oluşması açısından işbirliği tecrübesinin ayrı bir önemi vardır. İşbirliğini etkileyen bir değişken ise liderlik becerisi olup, tarımın karakteristik yapısından dolayı risklerin ve belirsizliklerin fazla olması yönetimsel sorunların oluşmasına neden olmaktadır. Yapılan çalışma ile birlikte işbirliği tecrübe katsayısı Çizelge 7'de gösterilmiştir. Buna göre işbirliği tecrübesinin kategori ortalaması 3.52 olarak hesaplanmıştır.

Tarım işletmelerinde inovasyon ve girişimciliğin gelişmesinde işbirliğinin önemli bir etkisi vardır (Andersson \& Karlsson, 2004). Tarım işletmelerinde işbirliğini sağlanması sadece yeni teknolojilerinin kullanılmasını değil, aynı zamanda işletmeleri etkileyebilecek ileri teknolojileri yaratma metotlarının öğrenilmesini de sağlamaktadır. Bu nedenle işletmelerde işbirliğinin etkin kullanımı işletmenin daha hızlı bir şekilde yüksek performanslı bir yapıya kavuşmasını sağlayacaktır.

Tarım işletmelerinde girişimcilik düzeyi 5 bileşene ayrılarak incelenmiştir. Belirlenen bu bileşenlerin ayrı ayrı skorları hesaplanmış ve girişimcilik katsayısı 3.75 olarak bulunmuştur. Bu değer büyük ölçekli işletmelerde 3.95, orta ölçekli işletmelerde 3.54 ve küçük ölçekli işletmelerde ise 3.17 olarak belirlenmiştir (Çizelge 8). Elde edilen bu skorlara göre işletme büyüklüklerinin artması ile girişimcilik katsayısı artmaktadır. 
Çizelge 7. İşletme büyüklüklerine göre İş birliği tecrübe skorları

Table 7. Collaboration experience scores by enterprise size

\begin{tabular}{|c|c|c|c|c|c|c|}
\hline \multirow[b]{2}{*}{$\begin{array}{c}\text { Kategoriler } \\
\text { Category }\end{array}$} & \multirow[b]{2}{*}{$\begin{array}{l}\text { Değişkenler } \\
\text { Variables }\end{array}$} & \multirow[b]{2}{*}{$\begin{array}{l}\text { Göstergeler } \\
\text { Indicators }\end{array}$} & \multicolumn{4}{|c|}{$\begin{array}{l}\text { İşletme büyüklüğü (dekar) } \\
\text { Enterprise size(decare) }\end{array}$} \\
\hline & & & $0-50$ & $51-150$ & 151-+ & $\begin{array}{l}\text { İşletmeler } \\
\text { ortalaması } \\
\text { Average of } \\
\text { enterprises }\end{array}$ \\
\hline \multirow{15}{*}{$\begin{array}{l}\text { İşbirliği } \\
\text { Tecrübesi } \\
\text { (Collaboration } \\
\text { Experience) }\end{array}$} & \multirow{4}{*}{$\begin{array}{l}\text { Diğer } \\
\text { üreticilerle iş } \\
\text { birliği becerisi } \\
\text { (Skills to co- } \\
\text { operate with } \\
\text { other farmers) }\end{array}$} & $\begin{array}{l}\text { Ortağa ve kiraya arazi işleme } \\
\text { (Land and leased land processing) }\end{array}$ & 4.11 & 4.02 & 4.29 & 4.19 \\
\hline & & $\begin{array}{l}\text { Makine ve işgücünde yardımlaşma } \\
\text { (Machinery and labor aids) }\end{array}$ & 2.49 & 2.87 & 3.23 & 3.05 \\
\hline & & $\begin{array}{l}\text { Diğer üreticilerle iş birliği } \\
\text { (Cooperation with other } \\
\text { manufacturers) }\end{array}$ & 2.36 & 2.73 & 2.96 & 2.84 \\
\hline & & $\begin{array}{l}\text { Değişken ortalaması } \\
\text { (Variable averages) }\end{array}$ & 2.99 & 3.21 & 3.49 & 3.36 \\
\hline & \multirow{5}{*}{$\begin{array}{l}\text { Takım } \\
\text { Çalışması } \\
\text { Becerisi } \\
\text { (Team-Working } \\
\text { Skills) }\end{array}$} & Yaş (Age) & 3.95 & 3.52 & 3.28 & 3.41 \\
\hline & & Eğitim (Education) & 2.18 & 2.79 & 3.68 & 3.27 \\
\hline & & $\begin{array}{l}\text { İş bölümü ve uzmanlaşma } \\
\text { (Department of business and } \\
\text { specialization) }\end{array}$ & 1.49 & 2.23 & 2.69 & 2.44 \\
\hline & & $\begin{array}{l}\text { İş planlaması } \\
\text { (Business planning) }\end{array}$ & 2.46 & 3.67 & 4.15 & 3.86 \\
\hline & & $\begin{array}{l}\text { Değişken ortalaması } \\
\text { (Variable averages) }\end{array}$ & 2.52 & 3.05 & 3.45 & 3.24 \\
\hline & \multirow{5}{*}{$\begin{array}{l}\text { Liderlik Becerisi } \\
\text { (Leadership } \\
\text { Skills) }\end{array}$} & Yaş (Age) & 3.95 & 3.52 & 3.28 & 3.41 \\
\hline & & Karar verme (To Decide) & 4.23 & 4.55 & 4.90 & 4.73 \\
\hline & & Deneyim (Experience) & 3.23 & 3.15 & 3.89 & 3.59 \\
\hline & & $\begin{array}{l}\text { Sorun çözme } \\
\text { (Solve problem) }\end{array}$ & 3.48 & 3.91 & 4.34 & 4.13 \\
\hline & & $\begin{array}{l}\text { Değişken ortalaması } \\
\text { (Variable averages) }\end{array}$ & 3.72 & 3.78 & 4.10 & 3.97 \\
\hline & \multicolumn{2}{|c|}{$\begin{array}{l}\text { Kategori ortalaması } \\
\text { (Category average) }\end{array}$} & 3.08 & 3.35 & 3.68 & 3.52 \\
\hline
\end{tabular}

Çizelge 8. Tarım işletmelerinin girişimcilik katsayısı

Table 8. Entrepreneurial coefficient of agricultural enterprises

\begin{tabular}{|c|c|c|c|c|}
\hline & \multicolumn{4}{|c|}{$\begin{array}{c}\text { İşletme büyüklüğü (dekar) } \\
\text { Enterprise size(decare) }\end{array}$} \\
\hline & $0-50$ & $51-150$ & $151-+$ & $\begin{array}{c}\text { İşletmeler ortalaması } \\
\text { (Average of enterprises) }\end{array}$ \\
\hline $\begin{array}{l}\text { Profesyonel tecrübe } \\
\text { (Professional skills) }\end{array}$ & 3.45 & 3.75 & 4.16 & 3.97 \\
\hline $\begin{array}{l}\text { Yönetim tecrübesi } \\
\text { (Management skills) }\end{array}$ & 3.39 & 3.77 & 4.15 & 3.96 \\
\hline $\begin{array}{l}\text { Fırsat tecrübesi } \\
\text { (Opportunity skills) }\end{array}$ & 2.85 & 3.34 & 3.85 & 3.60 \\
\hline $\begin{array}{l}\text { Stratejik tecrübe } \\
\text { (Strategic skills) }\end{array}$ & 3.09 & 3.51 & 3.91 & 3.71 \\
\hline $\begin{array}{l}\text { İşbirliği tecrübesi } \\
\text { (Co-operation skills) }\end{array}$ & 3.08 & 3.35 & 3.68 & 3.52 \\
\hline $\begin{array}{l}\text { Genel ortalama } \\
\text { (Overall average) }\end{array}$ & 3.17 & 3.54 & 3.95 & 3.75 \\
\hline
\end{tabular}

Araştırma sonucunda profesyonel, yönetim, fırsat, stratejik ve iş birliği tecrübesinin sağlanmasının işletme başarısı üzerindeki etkisi yüksektir. Nitekim bu becerilerin işletme ölçeğine göre skorları hesaplanmış ve işletme ölçeğinin büyümesiyle bu tecrübe katsayılarının arttığı görülmektedir. $\mathrm{Bu}$ durum yapılan diğer çalışmalarda da görülmektedir. Benzer şekilde, Mandam (2010) Nijerya'da motivasyon eksikliği, finansman eksikliği, yetersiz yönetim becerileri, 
yetersiz altyapı ve vergilendirme hem gençleri hem de hanehalkı çiftçilerinin girişimciliğini engellediğini belirlemiştir. Duniya (2010) ise yetersiz kredi kaynaklarının, düşük verimliliğin, tarımsal girdi fiyatlarının yüksek olması ve yeterli sermayeye sahip olamamaları gibi faktörlerin girişimciliğin sınırlanmasına neden olduğunu ifade etmiştir.

\section{Sonuçlar}

Girişimciliğin hem gelişmiş hem de gelişmekte olan ülkelerde istihdam yaratmada ve ekonomik kalkınmada önemli katkıları vardır. Girişimcilik üretim yöntemleri ve süreçlerine inovasyon yoluyla dönüşüm getirmek için bir araç olarak giderek daha fazla tanınmakta, tarım ve diğer endüstrilerine daha fazla verimlilik getireceğine inanılmaktadır. Araştırma sonucu, girişimcilik faaliyetlerini destekleyen bir ortamın teşvik edilmesi durumunda girişimciliğin geliştirilebileceğini göstermiştir. Ayrıca, tarımsal girişimcilik alanındaki araştırmanın sosyal bilimlerin diğer alanlarında olduğu kadar ilerlemediği de kabul edilmiştir. Bugüne kadar, tarımsal bir ortamda girişimci performansına odaklanan bilimsel olarak yayınlanmış hiçbir model bulunmamaktadır. Girişimcilik odaklı tarım uygulamalarını teşvik etmek, tarım sektöründeki zorluklara potansiyel olarak bir çözüm sağlamak için böyle bir modele ihtiyaç vardır. Girişimcilik modelinin ilk aşamasında ise mevcut potansiyelin belirlenmesi yer almaktadır. Bu amaca yönelik olarak çalışma kapsamında hazırlanan girişimcilik indeksi ile girişimciliğin mevcut potansiyeli belirlenmiş olup girişimcilik katsayısı oluşturulmuştur. Bu katsayılar profesyonellik, yönetim, fırsat, stratejik ve işbirliği bileşenleri altında belirlenmiştir. Buna göre girişimcilik düzeyi 5 puan üzerinden 3.75 skor olarak belirlenmiş olup, bu oranın üzerinde yer alan işletmeler girişimci olarak nitelendirilmiştir. Çalışma kapsamında işletmelerin \%47.95'inin girişimci oldukları belirlenmiştir. Bu durum işletmelerin sahip olduğu girişimci özelliklerinin daha çok açığa çıkması gerektiğini ortaya koymaktadır. Nitekim küresel rekabet ortamında ancak rakiplerine üstünlük sağlayan işletmeler başarılı olarak değerlendirilmektedir. $\mathrm{Bu}$ sonucun elde edilebilmesi için ise girişimcilerin yeniden yapılandırımasına ve var olan girişimciliğin ortaya çıkarılması gerekmektedir.

Girişimciliğin yapılandırılması ve ortaya çıkarılması ise ancak oluşturulacak olan girişimcilik modeli ile mümkün olacaktır. Önerilen girişimcilik modelinin ikinci aşaması yerel güçlerin dinamiğine dayanmakta ve girişimciyi esas almaktadır. Modele göre devlet piyasa güçlerini uyarma yönünde politikalar izlemeli ve beşeri yatırımlara önem vermelidir. Beşerî yatırımın temelini eğitim ve politikaların temel aktörlerini ise girişimciler oluşturmaktadır. Devlet altyapıya son derece önem vermeli, cazibe merkezleri anlayışı klâsik anlayıştan farklı olmalı ve daha çok sağlık, eğitim, güvenlik şeklinde hizmetlerin dağıtıldığı merkezler olarak düşünülmelidir. Önerilen modele göre, özelleştirmeye genel çerçeveden bakılmalı ve piyasa mekanizmasını uyaracak, tekelleşmeyi önleyecek, verimliliği artıracak şekilde özelleştirme yapılmalıdır. Aksi takdirde, özel tekeller yaratan özelleştirmeler bazı rantlar oluşturmaktan öteye gidemeyecektir. Nitekim daha önce Türkiye'de tarım sektöründe yapılan özelleştirmeler incelendiğinde başarılı örneklerin sayısı az olmakla birlikte, bu işletmelerin hem istihdamda hem de üretimdeki payları özelleştirmeden sonra düşüşe geçtiği görülmüştür. $\mathrm{Bu}$ nedenle yöresel girişimcilere sermaye desteği sağlanarak özelleştirmeden olumlu sonuçlar alınabilecektir.

Modelin üçüncü aşaması olan tarımsal girişimcilik ekosisteminin oluşturulması ve güçlendirilmesi, girişimcilere bilgi sunacak, ulusal ve uluslararası kaynakları aktaracak, proje stoku önerecek yerel kalkınma örgütlerini oluşturacaktır. $\mathrm{Bu}$ örgütlerin sadece merkezi örgütün bürokratlarından değil, katılımla oluşması ve performans ilkelerine göre çalışabilen özerk örgütler olması istenmektedir. Dördüncü aşama olarak düşünülen kalkınmanın finansmanı için bütçeye dayalı merkezi bir fonun oluşturulması, dış kaynaklardan sağlanacak kredilerden 
yararlanılması ve özel finansal kurumların yönlendirilmesi planlanmaktadır. Bu aşamada son yıllarda çeşitli kurum ve kuruluşlar tarafından bu durumun gerçekleştirilmesine rağmen, üreticilere bu kaynakların ulaştırılmasına yönelik iletişimin çiftçi-üniversite-özel sektör-devlet ekosisteminde oluşturulması gerekmektedir. Son olarak mevcut teşvik sisteminde köklü bir değişiklik yapılması ve böylece teşviklerin son derece açık, basit, uygulanabilir ve etkin olması sağlanmalıdır.

Genel olarak önerilen girişimcilik modeli benimsenirse, ortaya konulan belirli kriterlere uyum sağlayanlar bölge ve sektör ayırt etmeksizin teşviklerden yararlanabilecektir. Bu model ile var olan girişimciliğin ortaya çıkarılması sağlanmış olacaktır. Ayrıca oluşturulan indeks ile birlikte farklı bölgelerdeki tarım işletmelerinde girişimcilik düzeylerinin hesaplanabilmesi ve karşılaştırılmasına imkân sağlanmış olacaktır.

\section{Ekler}

$\mathrm{Bu}$ çalışmada kullanılan veriler Selçuk Üniversitesi Bilimsel Araştırmalar Koordinatörlüğü tarafından desteklenen 17201049 no'lu projeden alınmıştır.

\section{Kaynaklar}

Andersson, M., \& Karlsson, C. (2004). The role of accessibility for the performance of regional innovation systems. Knowledge spillovers and knowledge management, 283(9), 1-24.

Bayramoğlu, Z., Karakayacı, Z., \& Candemir, S. (2013, September). Küçük ve Orta Ölçekli Tarım İşletmelerinde Girişimcilik. Paper presented at the 7th international Academic Conference, Prague, Czech Republic.

Çınar, G., Armağan, G., Özden, A., \& Çınar, N., (2017). Çiftçiler İçin Girişimcilik Ölçeği Geliştirilmesi ve Çiftlik Performansı Üzerindeki Etkisi. Turkish Journal of Agricultural Economics, 23(2), 323-333.

De Wolf, P., \& Schoorlemmer, H. (2007). Exploring the Significance of Entrepreneurship in Agriculture. Frick, Switzerland: Research Institute of Organic Agriculture FiBL.
De Wolf, P., Schoorlemmer, H., \& Rudmann, C. (2007). Important trends and required skills: an international synthesis.

Duniya, A. (2010). Challenges of Entrepreneurship Development in Agriculture for Job Creation in Nigerian. Paper presented at the Proceedings of the 24th Annual National Conference of Farm Management Association of Nigeria held at Adamawa State University.

FAO. (2017). In FAO Statistical Yearbook 2017. Retrieved from www.fao.org/docrep/015/i2490e/i2490e00.html

Lans, T., Verstegen, J., \& Mulder, M. (2011). Analysing, pursuing and networking: Towards a validated threefactor framework for entrepreneurial competence from a small firm perspective. International Small Business Journal, 29(6), 695-713.

Mandam, L. (2010, 11-14 October). Entrepreneurship Development and Nigerian Transformation Process: Prospects and Challenges in Agriculture. Paper presented at the Proceedings of the 24th Annual National Conference of Farm Management Association of Nigeria held at Adamawa State University,

McElwee, G. (2005). Developing entrepreneurial skills of farmers. A Literature Review of Entrepreneurship in Agriculture. Available on the ESoF-website: http://www.esofarmers.org/documents/ESoFliteratu rereview_000. pdf.

McElwee, G. (2008). A taxonomy of entrepreneurial farmers. International Journal of Entrepreneurship and Small Business, 6(3), 465-478.

Morgül, T., \& Ayan, M. (2013). İş Hayatında Profesyonellik. York Üniversitesi, İşletmecilik Bölümü,

Pyysiäinen, J., Anderson, A., McElwee, G., \& Vesala, K. (2006). Developing the entrepreneurial skills of farmers: some myths explored. International Journal of Entrepreneurial Behavior \& Research, 12(1), 2139.

Pyysiäinen, J., \& Vesala, K. (2007). Important trends and required skills in Finland. Exploring the Significance of Entrepreneurship in Agriculture. Research Institute of Organic Agriculture FiBL, Frick, Switzerland, 29-36.

TOB. (2017). http://www.tarim.gov.tr/Konular/MakroEkonomik-Gostergeler.

TÜiK

http://www.tuik.gov.tr/VeriBilgi.do?alt_id=1003.

Erişim Tarihi: 15.09.2017.

Verhees, F. J., Kuipers, A., \& Klopcic, M. (2011). Entrepreneurial proclivity and farm performance: The cases of Dutch and Slovenian farmers. The International Journal of Entrepreneurship and Innovation, 12(3), 169-177.

Yamane, T. (1967). Elementary sampling theory. Prentice Hall, 1st Edition, 405. 